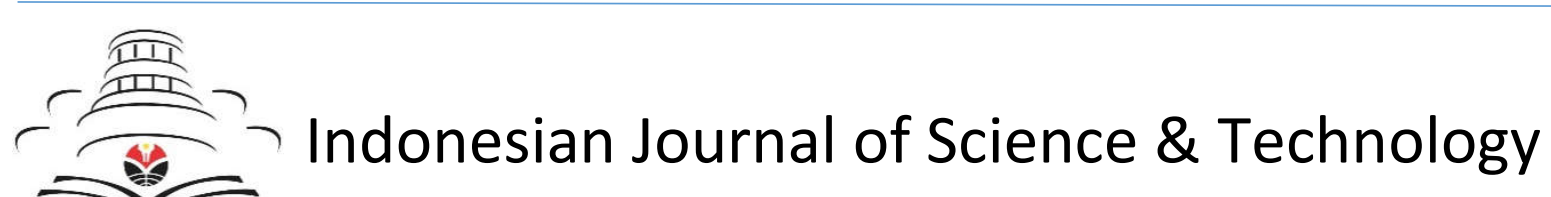

Journal homepage: http://ejournal.upi.edu/index.php/ijost/

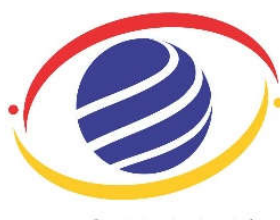

IJoST $T_{\text {Scionesce \& Journal of }}^{\text {Indnogy }}$

\title{
Artificial Neural Network Approach to Predict Biodiesel Production in Supercritical tert-Butyl Methyl Ether
}

Obie Farobie $^{1,2} *$ and Nur Hasanah ${ }^{3}$

${ }^{1}$ Division of Energy and Environmental Engineering, Institute of Engineering, Hiroshima University, 1-4-1 Kagamiyama, Higashi-Hiroshima, 739-8527, Japan

${ }^{2}$ Surfactant and Bioenergy Research Center (SBRC), Bogor Agricultural University, Jl. Padjajaran No.1, Bogor 16144, Indonesia

${ }^{3}$ Department of Information Engineering, Hiroshima University, 1-4-1 Kagamiyama, Higashi-Hiroshima, 739-

8527, Japan

*Corresponding author: Email: obie@hiroshima-u.ac.jp; Tel.: +81 8038964984

A B STR A C T

In this study, for the first time artificial neural network was used to predict biodiesel yield in supercritical tert-butyl methyl ether (MTBE). The experimental data of biodiesel yield conducted by varying four input factors (i.e. temperature, pressure, oil-to-MTBE molar ratio, and reaction time) were used to elucidate artificial neural network model in order to predict biodiesel yield. The main goal of this study was to assess how accurately this artificial neural network model to predict biodiesel yield conducted under supercritical MTBE condition. The result shows that artificial neural network is a powerful tool for modeling and predicting biodiesel yield conducted under supercritical MTBE condition that was proven by a high value of coefficient of determination $(R)$ of $0.9969,0.9899$, and 0.9658 for training, validation, and testing, respectively. Using this approach, the highest biodiesel yield was determined of $0.93 \mathrm{~mol} / \mathrm{mol}$ (corresponding to the actual biodiesel yield of $0.94 \mathrm{~mol} / \mathrm{mol}$ ) that was achieved at $400{ }^{\circ} \mathrm{C}$, under the reactor pressure of 10 $\mathrm{MPa}$, oil-to-MTBE molar ratio of $1: 40$ within $15 \mathrm{~min}$ of reaction time.

(C) 2016 Tim Pengembang Journal UPI

\begin{tabular}{l}
\multicolumn{1}{c}{ A R T I C L E I N F O } \\
Article History: \\
Submitted/ Received 2 Jan 2016 \\
First Revised 18 Feb 2016 \\
Accepted 23 Mar 2016 \\
First Available online 29 Mar 2016 \\
Publication Date 01 Apr 2016
\end{tabular}

\section{Keywords:}

Artificial neural network Biodiesel

Supercritical

Tert-butyl methyl ether 


\section{INTRODUCTION}

Research on renewable energy field has enormously attracted researchers during the past few years due to the motivation to reduce gas emission, environmental pollution, and dependence on fossil fuel. Biodiesel has been well known as one of the promising renewable energies as a biodegradable, renewable, environmentally benign and clean-burning substitute for petroleum diesel fuel. (Pasqualino et al., 2006)

Over the past few decades, biodiesel has been produced in industry using conventional catalytic reactions, either acidic or alkaline. However, these catalytic methods are still facing the problems such as time consuming, a tremendous amount of waste water generated, and sensitivity to high free fatty acid and water content. Besides, tedious separation and purification in downstream steps need to be conducted in order to remove the impurities such as saponified side products and catalyst from biodiesel.

Biodiesel production using supercritical methanol or ethanol technology could answer the problems faced by conventional catalytic methods affording higher reaction rate, no catalyst requirement, shorter reaction time, and simpler separation and purification steps (Saka \& Kusdiana, 2001; Farobie \& Matsumura, 2015a; Farobie \& Matsumura, 2015b; Farobie \& Matsumura, 2015c; Farobie \& Matsumura, 2015d; Farobie et al., 2015e; Farobie et al., 2015f). However, the by-product glycerol is unavoidable, leading to the significant decrease of glycerol price in the market. To circumvent this problem, non-catalytic biodiesel production in supercritical MTBE was proposed. Using this new approach, fatty acid methyl ester (FAME) or biodiesel and glycerol tert-butyl ether (GTBE) were obtained (Farobie et al., 2014; Farobie \& Matsumura, 2015a; Farobie \& Matsumura, 2015c; Farobie \& Matsumura, 2015d). GTBE has a positive effect on quality of diesel fuel and provides reducing in carbon monoxide and particulate matter from incomplete combustion due to the presence of oxygen in its structure. (Frusteri et al., 2009)

A number of study on prediction of biodiesel production using artificial neural network was published recently (Badday et al., 2014; Farobie et al., 2015f). However, there has been no study on this artificial neural network approach to estimate biodiesel yield conducted in supercritical MTBE. Therefore, the objectives of this study are to assess how accurately this model to predict biodiesel yield achieved by supercritical MTBE and to determine the highest yield of biodiesel conducted in supercritical MTBE.

\section{EXPERIMENTAL METHOD}

\subsection{Reagents and materials}

The feedstock of canola oil was obtained from J-Oil Mills, Tokyo, Japan, and MTBE was purchased from Nacalai Tesque, Inc., Kyoto, Japan. Standard compounds of fatty acid methyl esters (methyl oleate, methyl linoleate, methyl linolenate, methyl palmitate, and methyl steareate) were purchased from Tokyo Chemical Industry Co., Ltd. (Tokyo, Japan). Triolein, diolein, and monoolein standards were purchased from Nacalai Tesque, Inc., Kyoto, Japan, SigmaAldrich, Co., Japan, and Tokyo Chemical Industry Co., Ltd., Japan, respectively. To prepare GC standard solutions, all chemicals (tricaprin and $\mathrm{n}$-hexane) used were of analytical grades.

\subsection{Transesterification reaction}

The transesterification reaction was carried out under supercritical MTBE condition using the flow reactor. Schematic design of reactor can be found elsewhere (Farobie et al., 2014). The reactor was made of SS 316 steel tubing (i.d., $1 \mathrm{~mm}$; o.d., 1.59 $\mathrm{mm}$ ) with a length of $1.5 \mathrm{~m}$. The feedstock 
and MTBE were fed into the reactor at the desired temperature and pressure. The obtained products were removed from the reactor after passing them through a filter and a back pressure regulator. In this study, the transesterification reaction was carried out in a temperature range of $200-500{ }^{\circ} \mathrm{C}$ and a pressure range of 6-15 $\mathrm{MPa}$. The molar ratio of the oil to MTBE used in this study was fixed at 1:40. The feedstock used in this study was canola oil.

\subsection{Analytical methods}

The products were analyzed using a gas chromatography (GC-390B; GL Sciences) with an apparatus consisting of a column (Supelco MET-Biodiesel w/int. $2 \mathrm{~m}$ guard column, Sigma Aldrich) and flame-ionization detector (FID). Argon was used as the carrier gas. The temperature program began at 50 ${ }^{\circ} \mathrm{C}$, first maintaining this temperature for 1 $\mathrm{min}$. The temperature was then inclined at a rate of $15{ }^{\circ} \mathrm{C} / \mathrm{min}$ to $250{ }^{\circ} \mathrm{C}$ and kept at this temperature for $10 \mathrm{~min}$. Finally, the temperature was increased to $380{ }^{\circ} \mathrm{C}$ at a rate of $15{ }^{\circ} \mathrm{C} / \mathrm{min}$ and kept at this temperature for $5 \mathrm{~min}$. The temperatures of the injector and detector were both set at $380{ }^{\circ} \mathrm{C}$. The standard and sample injection volumes were both $1 \mu \mathrm{L}$, and peak identification was achieved by comparing the retention times between the standard and sample compounds. The methyl ester content was calculated using a calibration curve on the basis of peak areas. Fatty acid methyl ester (FAME) yields from the experimental results were calculated by dividing the moles of product FAME by moles of fatty acid group in the initial triglyceride.

\subsection{Artificial Neural Network (ANN) modeling}

A typical structure of ANN consists of input layer, one or several hidden layers, and output layer. The input layers used in this study were temperature, pressure, reaction time, and oil-to-MTBE molar ratio. Meanwhile, the output layer used in this study was biodiesel yield. The number of hidden layer was elucidated by a heuristic procedure consisted of attempting several numbers of neurons until the MSE of response was examined. Neural network architecture for biodiesel production in supercritical MTBE is presented in Figure 1.

The experimental data obtained from the transesterification of canola oil in supercritical MTBE were used for network training to create the network model that could compute the predicted yield of biodiesel values from the 4 input reaction conditions (temperature, pressure, reaction time, and oil-to-MTBE molar ratio) using MATLAB R2013a software. LavenbergMarquardt back propagation algorithm was chosen in training process. The performance of the ANN was evaluated based on the coefficient of determination $(R)$ and mean squared error (MSE).

The data were randomly classified into three subsets, namely training, validation, and testing data. Firstly, training stage, $70 \%$ of data were randomly chosen from the experimental data set, and the weighted parameters of the connections were elucidated until minimum value of MSE between experimental and predicted biodiesel yield was achieved. Secondly, testing stage, $15 \%$ of data were randomly selected to test the "trained" ANN, and the ANN used the weighted parameters determined during the first stage. Lastly, validation stage, $15 \%$ of remaining data subsets were used to validate the final estimation of FAME yield by the ANN developed in the two stages as mentioned previously. 


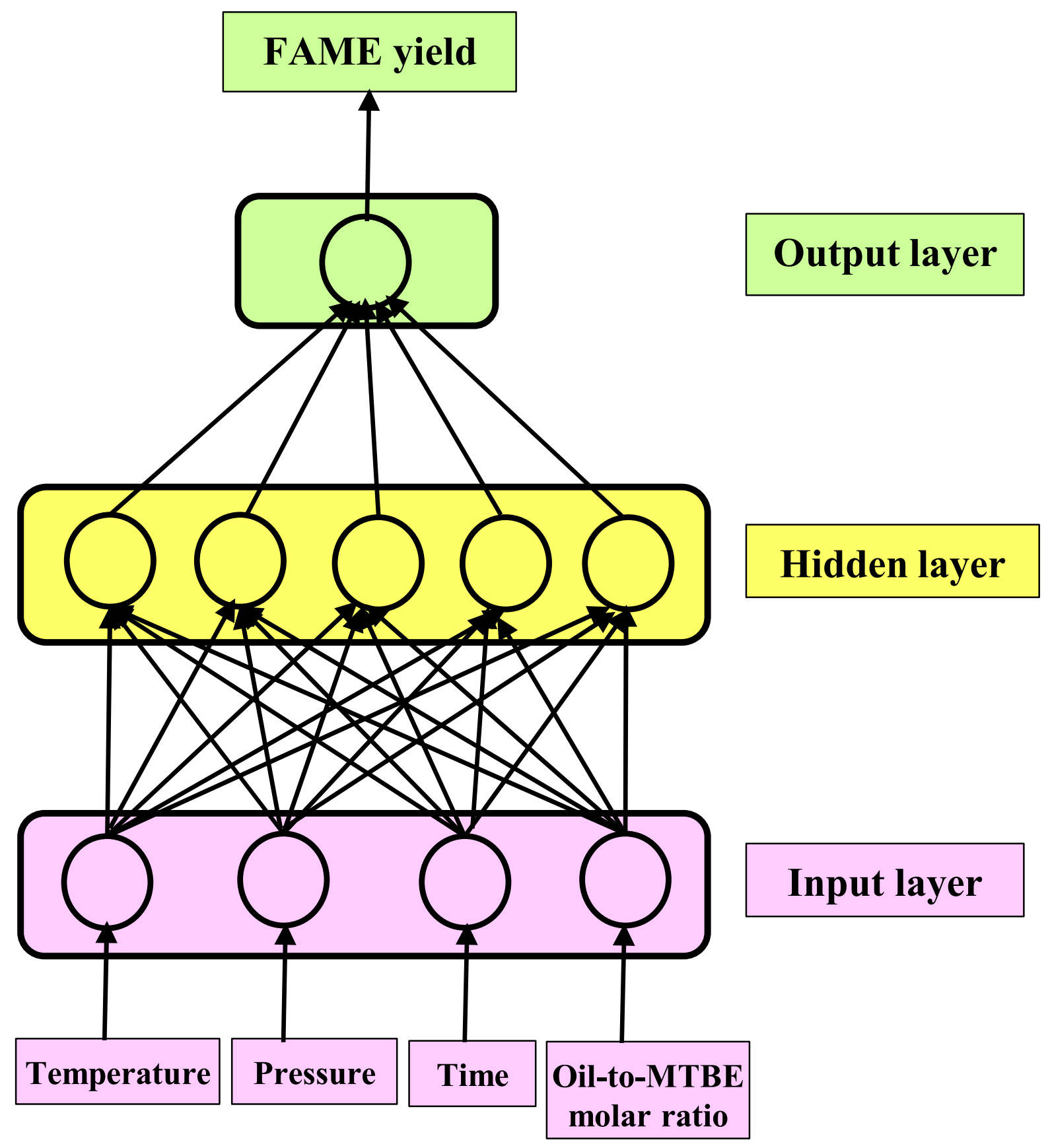

Figure 1. The neural network architecture for biodiesel production in supercritical MTBE.

\section{RESULTS AND DISCUSSION}

\subsection{Artificial neural network modeling}

Using the heuristic procedure, the optimum number of hidden neurons was determined. As observed in Figure 2. the optimum number of hidden neurons is 14 , giving the greatest $R$ values for training, validation, and testing of $0.9969,0.9899$, and 0.9658 , respectively and the lowest MSE values of $2.52 \times 10^{-4}, 2.62 \times 10^{-3}$, and $4.46 \times 10^{-}$ 3 , respectively. Thus, the optimum number of neurons that was used to create the network topology was 4-14-1, representing the neuron numbers in the input layer, the hidden layer, and the output layer, respectively. 

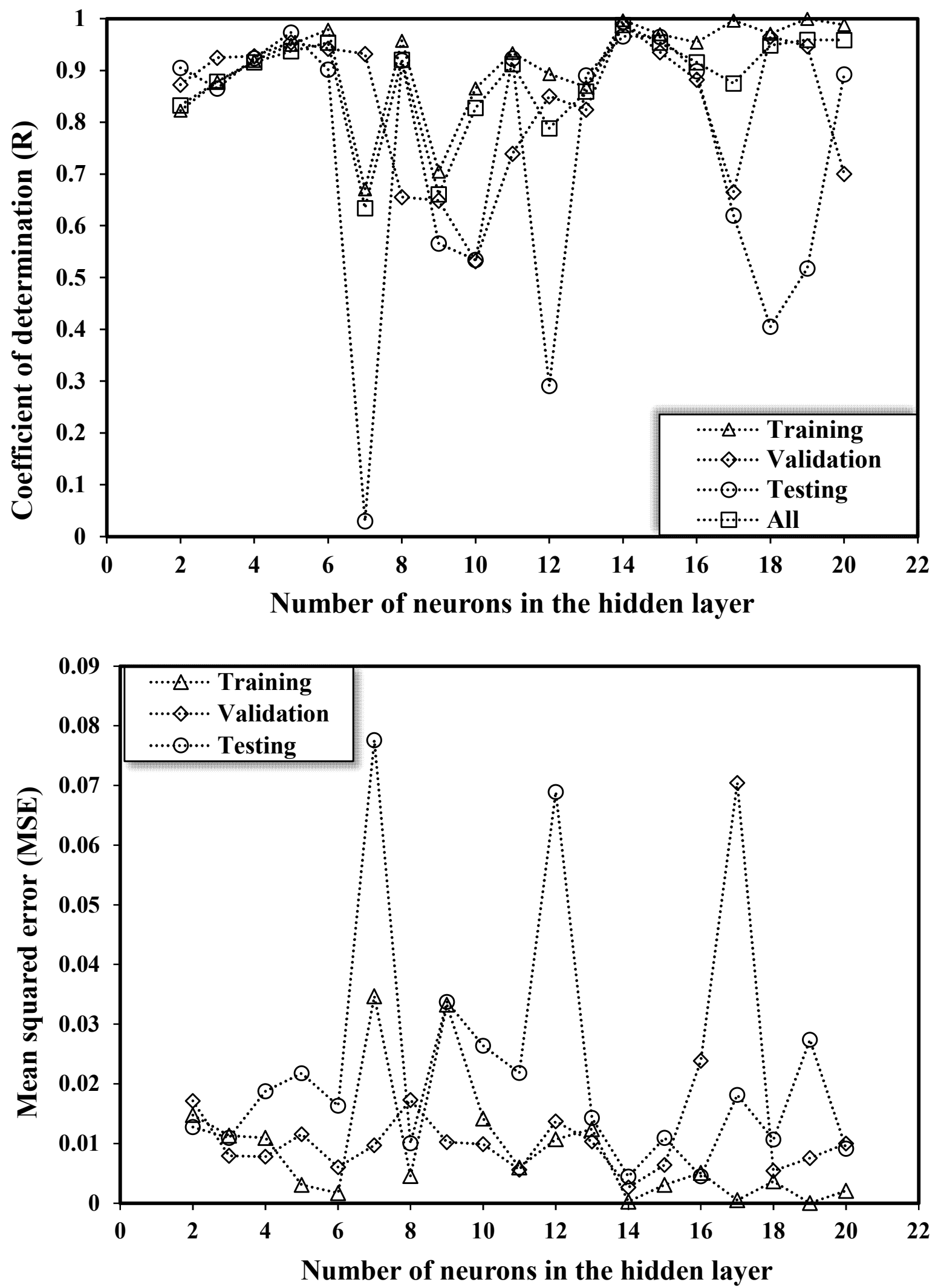

Figure 2. Heuristic determination of the optimum number of hidden neurons: coefficient of determination $(R)$ (upper Figure) and mean squared error (MSE) (lower Figure). 
Figure 3 reveals variations of the MSE value for training, validation, and testing of the ANN model with the 4-14-1 topology. We found that the results for the train, the validation, and the test were different. As observed in this Figure, the value of MSE decreased rapidly to a small value (MSE = $\left.2.62 \times 10^{-3}\right)$. After validation, the developed ANN was successfully used to predict a subset of 8 FAME samples chose randomly from the region of the testing subset.

\subsection{Prediction of biodiesel yield using ANN}

The results of the network models for biodiesel yield generated from transesterification of canola oil in supercritical MTBE for the optimum neuron number are presented in Table 1 . In this calculation, Lavenberg-Marquardt back propagation algorithm was used for network training. This algorithm is the best choice compared to any other algorithms since it can achieve the lowest standard deviation and mean square errors (Moradi et al., 2013).

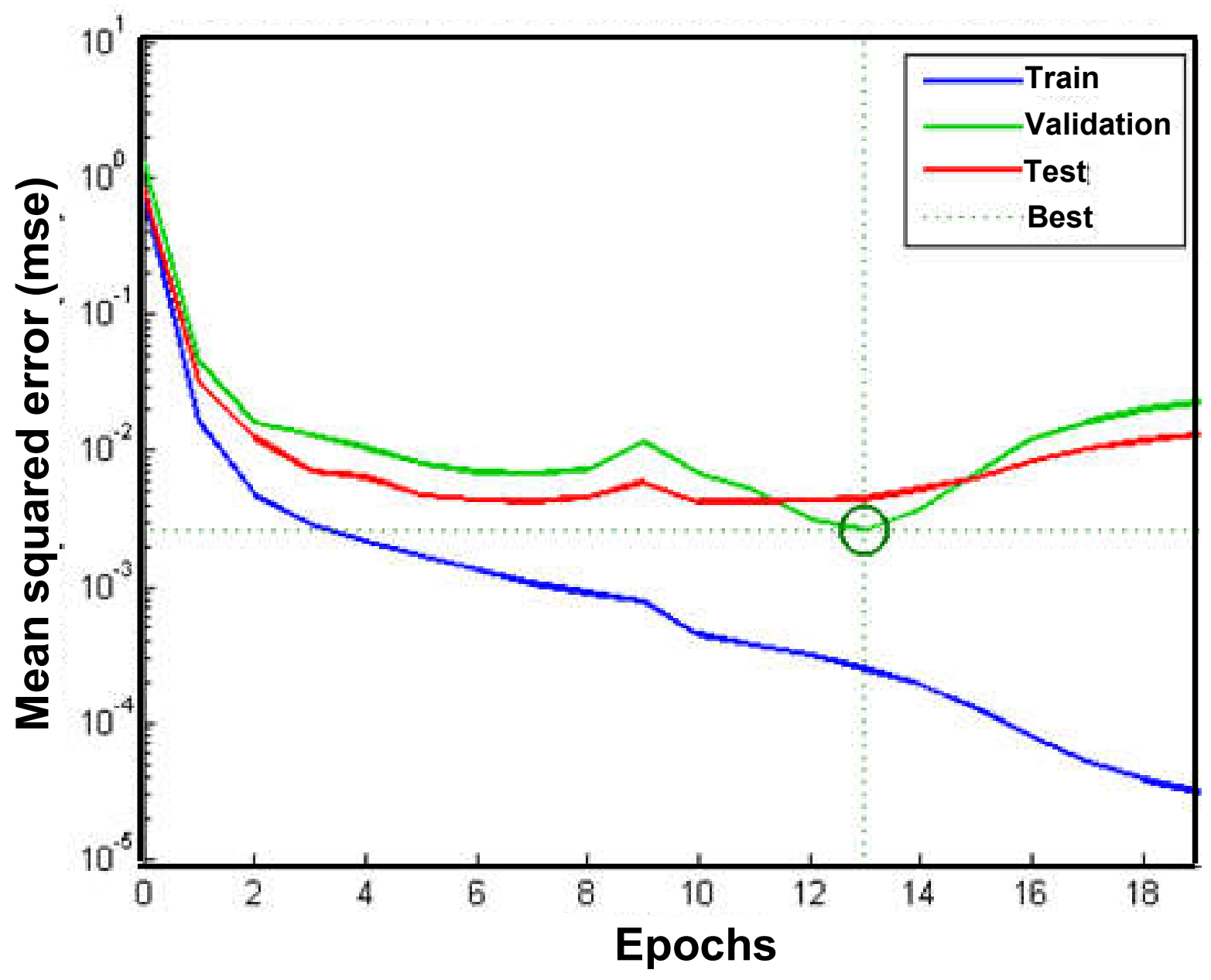

Figure 3. MSE values for training, validation, and testing of the ANN model. 
Table 1. Experimental and predicted yield of FAME by neural network using LavenbergMarquardt back propagation

\begin{tabular}{|c|c|c|c|c|c|c|c|}
\hline \multirow[b]{2}{*}{ Run } & \multicolumn{4}{|c|}{ Variables } & \multirow[b]{2}{*}{$\begin{array}{l}\text { Experimental } \\
\text { Yield [-] }\end{array}$} & \multirow[b]{2}{*}{$\begin{array}{l}\text { Predicted } \\
\text { Yield [-] }\end{array}$} & \multirow[b]{2}{*}{ Error } \\
\hline & $\begin{array}{c}\text { Temperature } \\
{\left[{ }^{\circ} \mathrm{C}\right]}\end{array}$ & $\begin{array}{c}\text { Pressure } \\
\text { [MPa] }\end{array}$ & $\begin{array}{l}\text { Reaction time } \\
\text { [min] }\end{array}$ & MTBE/Oil & & & \\
\hline 1 & 200 & 10 & 3 & 40 & 0.0367 & 0.0361 & 0.0006 \\
\hline 2 & 200 & 10 & 6 & 40 & 0.0751 & 0.1018 & 0.0267 \\
\hline 3 & 200 & 10 & 9 & 40 & 0.1568 & 0.1468 & 0.0100 \\
\hline 4 & 200 & 10 & 12 & 40 & 0.1824 & 0.1725 & 0.0099 \\
\hline 5 & 200 & 10 & 15 & 40 & 0.2001 & 0.1934 & 0.0067 \\
\hline 6 & 250 & 10 & 3 & 40 & 0.0910 & 0.0904 & 0.0006 \\
\hline 7 & 250 & 10 & 6 & 40 & 0.1828 & 0.1980 & 0.0152 \\
\hline 8 & 250 & 10 & 9 & 40 & 0.3141 & 0.2746 & 0.0395 \\
\hline 9 & 250 & 10 & 12 & 40 & 0.3405 & 0.3239 & 0.0166 \\
\hline 10 & 250 & 10 & 15 & 40 & 0.3709 & 0.3534 & 0.0175 \\
\hline 11 & 300 & 10 & 3 & 40 & 0.1708 & 0.1728 & 0.0020 \\
\hline 12 & 300 & 10 & 6 & 40 & 0.2408 & 0.2717 & 0.0309 \\
\hline 13 & 300 & 10 & 9 & 40 & 0.3456 & 0.3365 & 0.0091 \\
\hline 14 & 300 & 10 & 12 & 40 & 0.3708 & 0.3787 & 0.0079 \\
\hline 15 & 300 & 10 & 15 & 40 & 0.4107 & 0.3941 & 0.0166 \\
\hline 16 & 350 & 10 & 3 & 40 & 0.2165 & 0.2173 & 0.0008 \\
\hline 17 & 350 & 10 & 6 & 40 & 0.3291 & 0.3369 & 0.0078 \\
\hline 18 & 350 & 10 & 9 & 40 & 0.4145 & 0.4126 & 0.0019 \\
\hline 19 & 350 & 10 & 12 & 40 & 0.4368 & 0.4466 & 0.0098 \\
\hline 20 & 350 & 10 & 15 & 40 & 0.4427 & 0.4463 & 0.0036 \\
\hline 21 & 400 & 10 & 3 & 40 & 0.4210 & 0.4181 & 0.0029 \\
\hline 22 & 400 & 10 & 6 & 40 & 0.6640 & 0.6408 & 0.0232 \\
\hline 23 & 400 & 10 & 9 & 40 & 0.7881 & 0.7983 & 0.0102 \\
\hline 24 & 400 & 10 & 12 & 40 & 0.9414 & 0.8894 & 0.0520 \\
\hline 25 & 400 & 10 & 15 & 40 & 0.9402 & 0.9327 & 0.0075 \\
\hline
\end{tabular}


Table 1. (continue) Experimental and predicted yield of FAME by neural network using Lavenberg-Marquardt back propagation

\begin{tabular}{|c|c|c|c|c|c|c|c|}
\hline \multirow[b]{2}{*}{ Run } & \multicolumn{4}{|c|}{ Variables } & \multirow[b]{2}{*}{$\begin{array}{l}\text { Experimental } \\
\text { Yield [-] }\end{array}$} & \multirow{2}{*}{$\begin{array}{l}\text { Predicted } \\
\text { Yield [-] }\end{array}$} & \multirow[b]{2}{*}{ Error } \\
\hline & $\begin{array}{c}\text { Temperature } \\
{\left[{ }^{\circ} \mathrm{C}\right]}\end{array}$ & $\begin{array}{c}\text { Pressure } \\
{[\mathrm{MPa}]}\end{array}$ & $\begin{array}{l}\text { Reaction time } \\
\text { [min] }\end{array}$ & MTBE/Oil & & & \\
\hline 26 & 450 & 10 & 3 & 40 & 0.4371 & 0.4515 & 0.0144 \\
\hline 27 & 450 & 10 & 6 & 40 & 0.6149 & 0.6075 & 0.0074 \\
\hline 28 & 450 & 10 & 9 & 40 & 0.7433 & 0.6835 & 0.0598 \\
\hline 29 & 450 & 10 & 12 & 40 & 0.6950 & 0.6973 & 0.0023 \\
\hline 30 & 450 & 10 & 15 & 40 & 0.6861 & 0.6785 & 0.0076 \\
\hline 31 & 500 & 10 & 3 & 40 & 0.2586 & 0.2724 & 0.0138 \\
\hline 32 & 500 & 10 & 6 & 40 & 0.3368 & 0.2966 & 0.0402 \\
\hline 33 & 500 & 10 & 9 & 40 & 0.1937 & 0.2347 & 0.0410 \\
\hline 34 & 500 & 10 & 12 & 40 & 0.1306 & 0.1570 & 0.0264 \\
\hline 35 & 500 & 10 & 15 & 40 & 0.1104 & 0.1103 & 0.0001 \\
\hline 36 & 350 & 6 & 5 & 40 & 0.0907 & 0.0976 & 0.0069 \\
\hline 37 & 350 & 8 & 5 & 40 & 0.1127 & 0.2147 & 0.1020 \\
\hline 38 & 350 & 12 & 5 & 40 & 0.1112 & 0.1107 & 0.0005 \\
\hline 39 & 350 & 15 & 5 & 40 & 0.1113 & 0.1122 & 0.0009 \\
\hline 40 & 400 & 10 & 3 & 20 & 0.2154 & 0.2505 & 0.0351 \\
\hline 41 & 400 & 10 & 6 & 20 & 0.2262 & 0.2479 & 0.0217 \\
\hline 42 & 400 & 10 & 9 & 20 & 0.3068 & 0.2876 & 0.0192 \\
\hline 43 & 400 & 10 & 12 & 20 & 0.3365 & 0.3822 & 0.0457 \\
\hline 44 & 400 & 10 & 15 & 20 & 0.5573 & 0.5262 & 0.0311 \\
\hline 45 & 400 & 10 & 3 & 30 & 0.3386 & 0.3473 & 0.0087 \\
\hline 46 & 400 & 10 & 6 & 30 & 0.3700 & 0.3787 & 0.0087 \\
\hline 47 & 400 & 10 & 9 & 30 & 0.3947 & 0.4379 & 0.0432 \\
\hline 48 & 400 & 10 & 12 & 30 & 0.5073 & 0.5122 & 0.0049 \\
\hline 49 & 400 & 10 & 15 & 30 & 0.7366 & 0.5580 & 0.1786 \\
\hline 50 & 400 & 10 & 3 & 50 & 0.3764 & 0.3733 & 0.0031 \\
\hline
\end{tabular}


Table 1. (continue) Experimental and predicted yield of FAME by neural network using Lavenberg-Marquardt back propagation

\begin{tabular}{ccccccccc}
\hline Run & \multicolumn{9}{c}{ Variables } & $\begin{array}{c}\text { Experimental } \\
\text { Yield [-] }\end{array}$ & $\begin{array}{c}\text { Predicted } \\
\text { Yield [-] }\end{array}$ & Error \\
\cline { 2 - 8 } & $\begin{array}{c}\text { Temperature } \\
{\left[{ }^{\circ} \mathrm{C}\right]}\end{array}$ & $\begin{array}{c}\text { Pressure } \\
{[\mathrm{MPa}]}\end{array}$ & $\begin{array}{c}\text { Reaction time } \\
{[\mathrm{min}]}\end{array}$ & MTBE/Oil & & & \\
\hline 51 & 400 & 10 & 6 & 50 & 0.3781 & 0.3814 & 0.0033 \\
52 & 400 & 10 & 9 & 50 & 0.3802 & 0.3630 & 0.0172 \\
53 & 400 & 10 & 12 & 50 & 0.3829 & 0.3893 & 0.0064 \\
54 & 400 & 10 & 15 & 50 & 0.4963 & 0.4925 & 0.0038 \\
\hline
\end{tabular}

All data for FAME yield were tested to assess the prediction capability of ANN model. The results of FAME yield predicted by ANN model are compared with experimental data as presented in Figure 4. As shown in this Figure, almost all data show a good agreement, gave the coefficient determination $(R)$ for training, validation, testing, and all data of 0.9969, 0.9899, 0.9658 , and 0.9883 , respectively. Using the ANN approach, the highest FAME yield can be determined of $0.93 \mathrm{~mol} / \mathrm{mol}$ (corresponding to the actual FAME yield of $0.94 \mathrm{~mol} / \mathrm{mol}$ ) that was achieved at $400{ }^{\circ} \mathrm{C}$, under the reactor pressure of $10 \mathrm{MPa}$, oilto-MTBE molar ratio of 1:40 within 15 minutes of reaction time.

\subsection{Comparison between ANN and least square method}

Finally, the result of ANN was compared with least square method. The data of least square method was obtained from previous work of Farobie et al. (2014). Figure 5. shows comparison of experimental value and predicted FAME yield obtained using least square method and ANN model. As shown in this Figure, at lower temperature $\left(200-300{ }^{\circ} \mathrm{C}\right)$, the curve fitting using least square method gave a good agreement. However, at higher temperature (350-500 $\left.{ }^{\circ} \mathrm{C}\right)$, ANN model gave better results compared to least square method. Under these conditions, the $R$ values of 0.9994 , $0.9968,0.9922,0.9336$ were determined using ANN model, and those of 0.9768, $0.9519,0.9855$, and 0.8611 using least square method at $350,400,450$, and $500{ }^{\circ} \mathrm{C}$, respectively.

The parity plot comparing the experimental data for FAME yields with the calculated value by the least square method and ANN model are presented in Figure 6. As shown in this Figure, the model prediction using ANN gave $R$ value higher than that using least square method, confirming that ANN model had better generalization ability to predict FAME yield. 


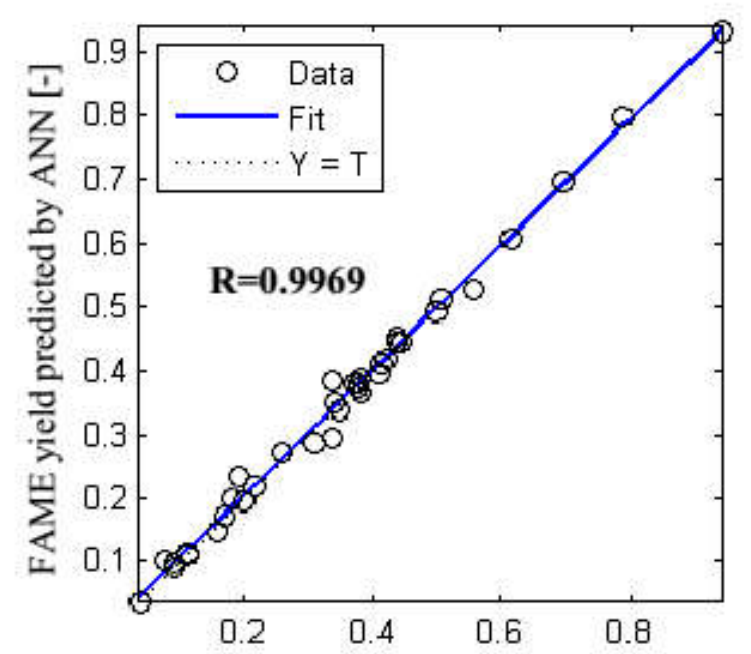

Experimental FAME yield [-] for training

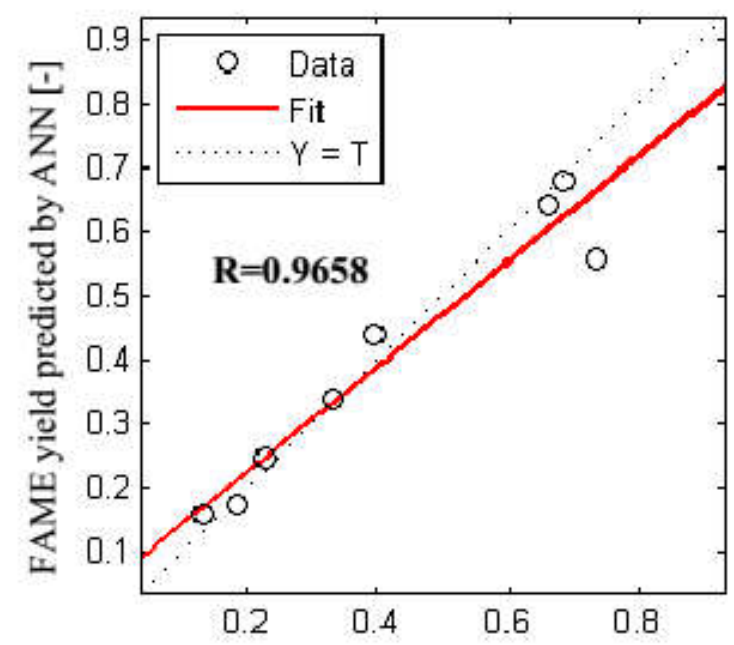

Experimental FAME yield [-] for testing

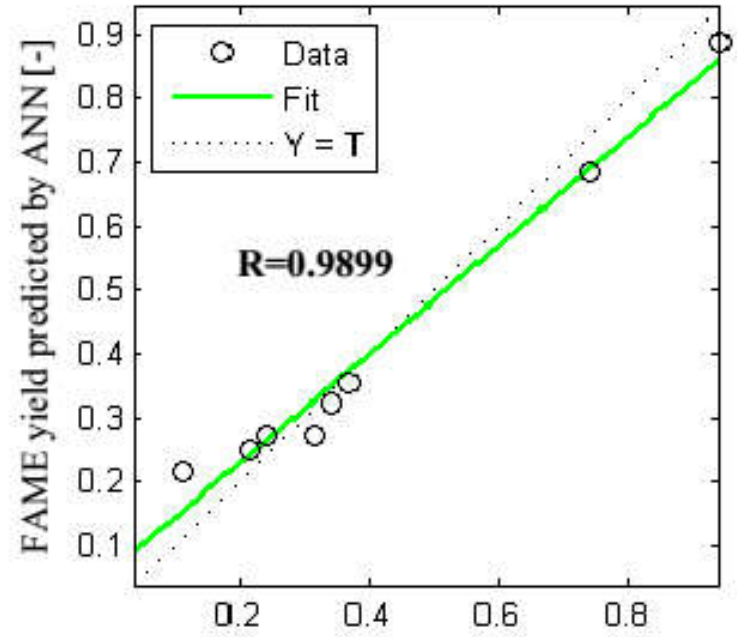

Experimental FAME yield [-] for validation

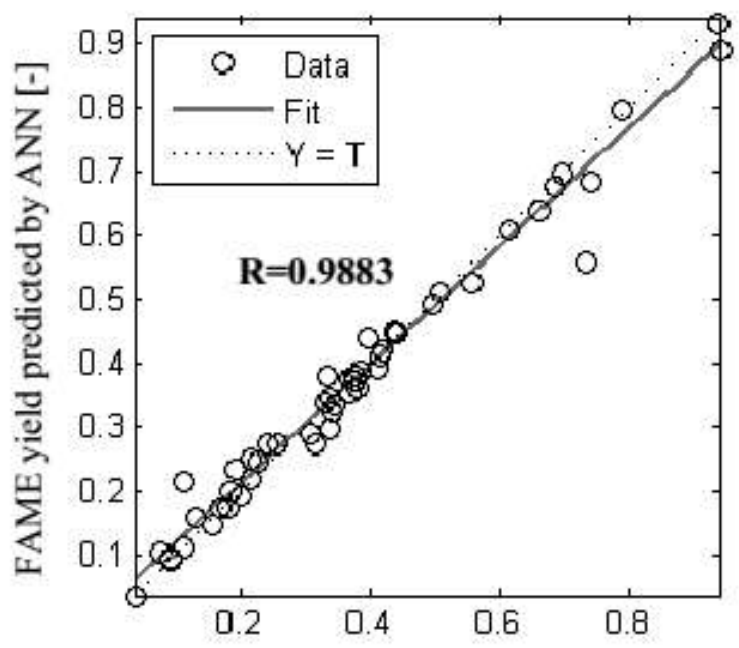

Experimental FAME yield [-] for all

Figure 4. Comparison of experimental and predicted value of FAME yield for training, validation, and testing of the ANN model. 

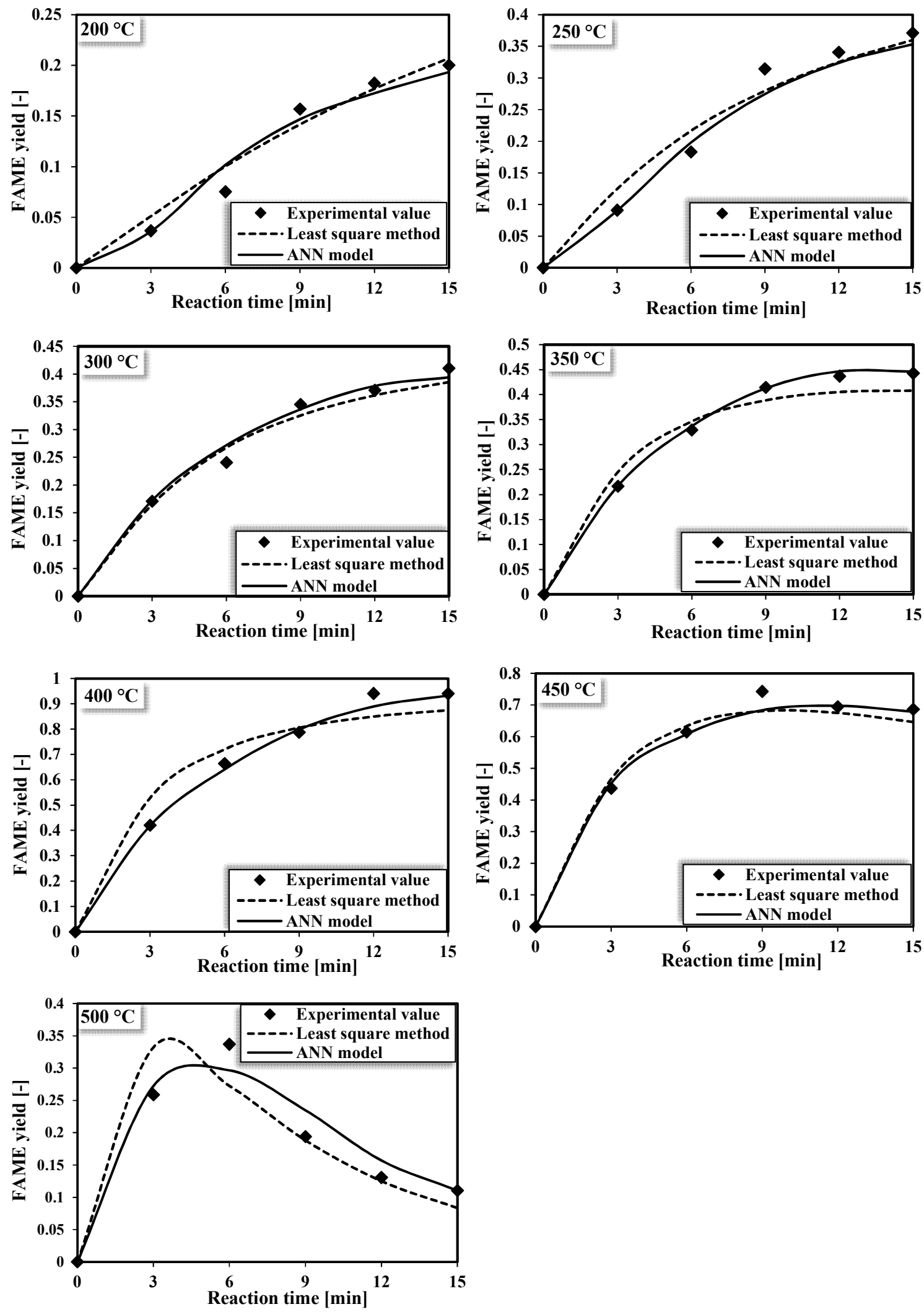

Figure 5. Comparison of experimental and calculated FAME yield using least square method and ANN model under various temperatures. 

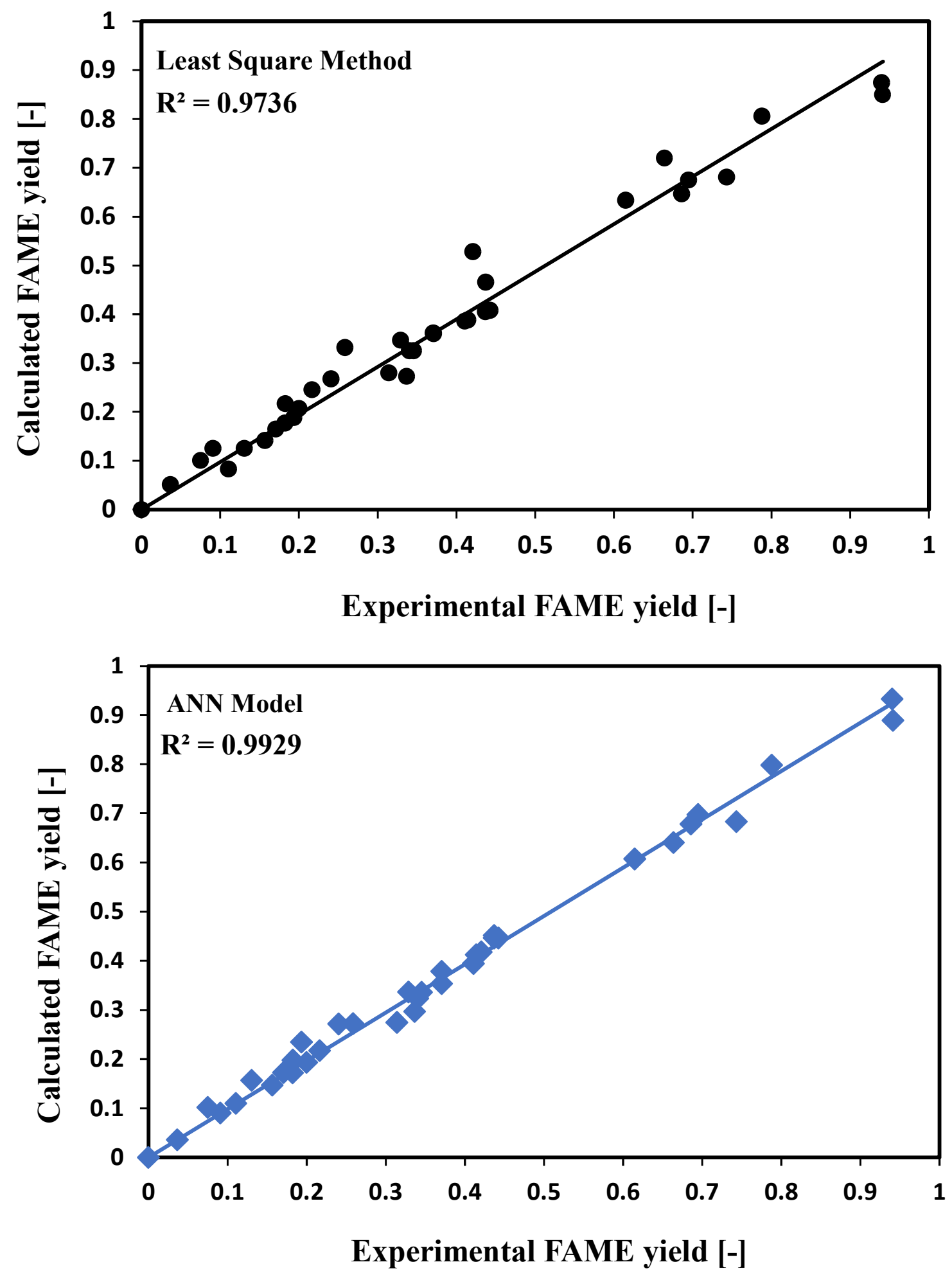

Figure 6. Comparison of parity plot using (a) least square method and (b) ANN model. 


\section{CONCLUSIONS}

ANN model was used to predict biodiesel yield conducted under supercritical MTBE condition. This study shows that ANN is a powerful tool for modeling and predicting biodiesel yield that was proven by a high value of coefficient of determination $(R)$ of $0.9969,0.9899$, and 0.9658 and a low value of mean squared error (MSE) of $2.52 \times 10^{-4}, 2.62 \times 10^{-3}$, and $4.46 \times 10^{-3}$ for training, validation, and testing, respectively. Using this technique, the highest FAME yield can be determined of $0.93 \mathrm{~mol} / \mathrm{mol}$ (corresponding to the actual FAME yield of $0.94 \mathrm{~mol} / \mathrm{mol}$ ) that was achieved at $400{ }^{\circ} \mathrm{C}$, under the reactor pressure of $10 \mathrm{MPa}$, oil-to-MTBE molar ratio of $1: 40$ within 15 min reaction time. The model prediction using ANN gave $R$ value higher than that using least square method, indicating that ANN model had better generalization ability to predict FAME yield.

\section{ACKNOWLEDGMENTS}

Nur Hasanah would like to acknowledge Indonesia Endowment Fund for Education/ Lembaga Pengelola Dana Pendidikan (LPDP) scholarship for her PhD study in Hiroshima University, Japan.

\section{AUTHOR'S NOTES}

The author(s) declare(s) that there is no conflict of interest regarding the publication of this article. Authors confirmed that the data and the paper are free of plagiarism.

\section{REFERENCES}

Badday, A.S., Abdullah, A.Z., and Lee, K. (2014) Artificial neural network approach for modeling of ultrasound-assisted transesterification process of crude Jatropha oil catalyzed by heteropolyacid based catalyst. Chemical engineering, and processing: process intensification, 75, 31-37.

Farobie, O., and Matsumura, Y. (2015a) A comparative study of biodiesel production using methanol, ethanol, and tert-butyl methyl ether (MTBE) under supercritical conditions. Bioresource technology, 191, 306-311.

Farobie, O., and Matsumura, Y. (2015b) Biodiesel production in supercritical methanol using a novel spiral reactor. Procedia environmental sciences, 28(SustaiN 2014), 204-213.

Farobie, O., and Matsumura, Y. (2015c) Effect of pressure on biodiesel production in supercritical tert butyl methyl ether (MTBE). Journal of the japan institute of energy, $94,755-762$.

Farobie, O., and Matsumura, Y. (2015d) Effectiveness of spiral reactor for biodiesel production using supercritical t-butyl methyl ether (MTBE). Journal of the japan petroleum institute, 58(2), 110-117.

Farobie, O., Sasanami, K., and Matsumura, Y., (2015e) A novel spiral reactor for biodiesel production in supercritical ethanol. Applied energy, 147, 20-29.

Farobie, O., Hasanah, N., and Matsumura, Y. (2015f) Artificial neural network modeling to predict biodiesel production in supercritical methanol and ethanol using spiral reactor. Procedia environmental sciences, 28(SustaiN 2014), 214-223. 
36 | Indonesian Journal of Science \& Technology, Volume 1 Issue 1, April 2016 Hal 23-36

Farobie, O., Yanagida, T., and Matsumura, Y. (2014) New approach of catalyst-free biodiesel production from canola oil in supercritical tert-butyl methyl ether (MTBE). Fuel, 135, 172-181.

Frusteri, F., Arena, F., Bonura, G., Cannilla, C., Spadaro, L., and Di Blasi, O. (2009) Catalytic etherification of glycerol by tert-butyl alcohol to produce oxygenated additives for diesel fuel. Applied catalysis A: General, 367(1), 77-83.

Moradi, G. R., Dehghani, S., Khosravian, F., and Arjmandzadeh, A. (2013) The optimized operational conditions for biodiesel production from soybean oil and application of artificial neural networks for estimation of the biodiesel yield. Renewable energy, 50, 915-920.

Pasqualino, J.C., Montane, D., and Salvado, J. (2006) Synergic effects of biodiesel in the biodegradability of fossil-derived fuels. Biomass and bioenergy, 30, 874-879.

Saka, S., and Kusdiana, D. (2001) Biodiesel fuel from rapeseed oil as prepared in supercritical methanol. Fuel, 80, 225-231. 